\title{
Trisomy 18 after assiduous prenatal diagnosis mimicking molar pregnancy: A case
}

\author{
Sofoudis $\mathrm{C}^{1 *}$, Moschopoulou $\mathrm{S}^{1}$, Dtailiani $\mathrm{P}^{2}$, Theodoropoulos $\mathrm{P}^{3}$, Manolakos $\mathrm{E}^{4}$ and Papoulidis $\mathrm{I}^{4}$ \\ ${ }^{1}$ Department of Obstetrics and Gynecology, Konstandopoulio General Hospital, Athens, Greece \\ ${ }^{2}$ Department of Pathology, Konstandopoulio General Hospital, Athens, Greece \\ ${ }^{3}$ Obstetrician Gynecologist, Fetal Medicine Specialist, Athens, Greece \\ ${ }^{4}$ Clinical Laboratory Genetics, Athens, Greece
}

\begin{abstract}
Trisomy 18 or Edwards Syndrome, represents a rare entity throughout current bibliography consisting in most of cases a variety of anatomic abnormalities or endometrial fetal deficit. Prenatal diagnosis with NT (Nuchal Translucency) measurement followed by invasive methods such as CVS (Chorionic villus sampling) or Amniocentesis can easily diagnose such cases, recommending proper therapeutic mapping.

Few cases with imaging findings inside normal ranges, can easily conceal chromosomal abnormalities, hardly detected, leading to eventful pregnancy. Molar pregnancy consists a multi systematic clinical entity, depicting as a abnormal form of pregnancy in which a non-viable fertilized egg implants in the uterus and will fail to come to term.

Focusing on current bibliography, Trisomy 18 or Edwards Syndrome in terms of histopathologic evaluation can mimic clinical elements of molar pregnancy. Aim of our study reflects the presentation of such rare case, properly diagnosed and treated.
\end{abstract}

\section{Introduction}

Edwards Syndrome, also known as trisomy 18, represents a genetic disorder strongly associated with presence of a third copy of all or part of chromosome 18 [1]. Most cases occur due to obstacles during formation of reproductive cells or during early development. Incidence of Edwards Syndrome still increases with mother's age. There are few cases in current bibliography inherited from a person's parents [2]. We must also mention cases of mosaic trisomy, not revealing chromosomal trisomy [3].

Gold standard of assiduous prenatal diagnosis consists measuring of NT (Nuchal Translucency) and due to pathologic imaging findings, performance of CVS (Chorionic villus sampling) and karyotype evaluation.

\section{Case}

We present a case of a 30-year-old female patient (G0, P0) with history of use of antidepressant agents, gastric sleeve and smoking during pregnancy attended at our Department for regular prenatal monitoring.

In $13 \mathrm{w}$ of gestation, and all laboratory examinations of 1 st trimester in normal ranges, patient attended at specialized fetal medicine center in order to perform NT (Nuchal Translucency) measurement.

Ultra-sonographic evaluation revealed NT (Nuchal Translucency) $2.5 \mathrm{~mm}$ (cut-off limit $2.5 \mathrm{~mm}$ ), nasal bone visible, measuring free-beta chorionic gonadotropin 9,19 IU/L equivalent with $0,451 \mathrm{MoM}$ and PAPP-A (Pregnancy associated plasma protein) 0,600 IU/L equivalent with 0,626 MoM respectively. Modified possibility for T21 1/874, T18 $1 / 2708$ and $\mathrm{T} 131 / 5335$ respectively.
All laboratory markers measured in normal ranges. Fortunately, performance of CVS (Chorionic villus sampling) and further karyotype evaluation, revealed presence of Trisomy in chromosome 18 or Edward Syndrome.

After assiduous informing, couple decided therapeutic uterine evacuation. Final histopathologic evaluation revealed presence of dilated sinuidal areas with hydroponic degeneration and trophoblastic hyperplasia. All these characteristics compose configuration of molar pregnancy (Figures 1 and 2). Patient discharged the hospital next pod in good clinical condition.

\section{Discussion}

Trisomy 18, also called Edwards Syndrome, consists a chromosomal condition associated with plenty phenotypic abnormalities [4]. Cases, which succeed in completing pregnancy, often have slow growth before birth (intrauterine growth retardation) and a low birth weight. Many affected embryos may develop heart defects or other anatomic abnormalities. Other develop abnormally shaped head; a small jaw and mouth; and clenched fists with overlapping fingers [5]. Majority of cases, due to several life-threatening medical problems, die before birth or within their first month.

${ }^{\star}$ Correspondence to: Chrisostomos Sofoudis, MD, PhD, MPH, Ippokratous 209, 11472, Athens, Greece, E-mail: chrisostomos.sofoudis@gmail.com

Key words: trisomy 18, molar pregnancy, chorionic villus sampling, nuchal translucency

Received: March 09, 2020; Accepted: : March 18, 2020 Published: March 25, 2020 


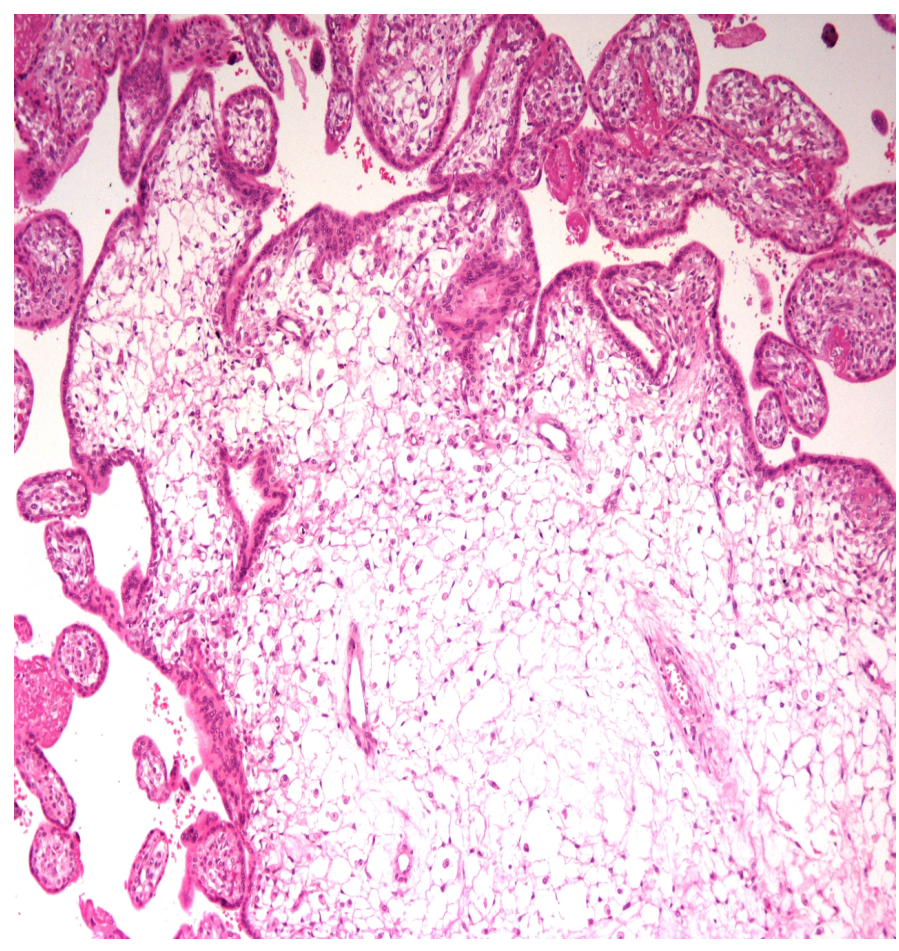

Figure 1. Edema of chorionic villus with irregular surface, hydrophobic degeneration, enlarged vaginal spaces, enclosed areas penetrating stroma, revealing minimal cytotrophoblastic hyperplasia. H\&E X 100

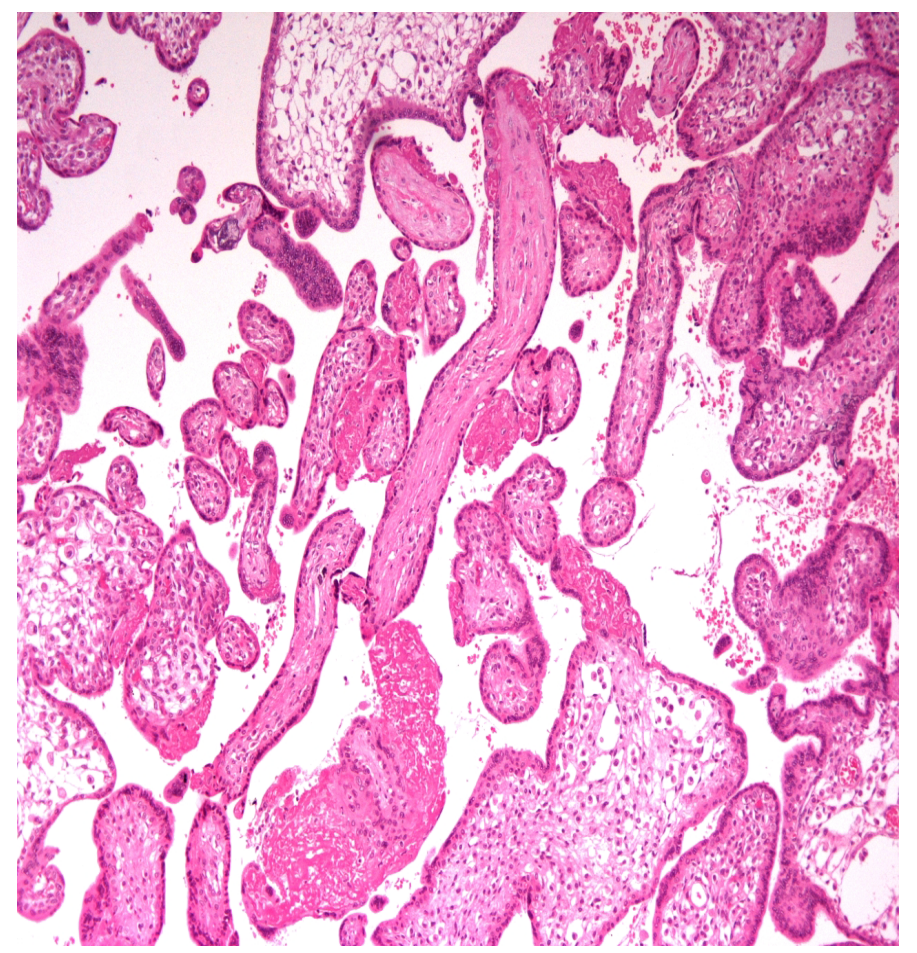

Figure 2. Small size chorionic villus revealing stroma fibrosis. H\&E X200
Incidence of $5-10 \%$ live until one year of age, performing severe intellectual disability [6]. Few cases in current literature, in terms of histopathologic evaluation, reveal elements of molar pregnancy in fetal remnants of Trisomy 18 or Edwards Syndrome. Hydroponic degeneration, presence of trophoblastic tissue and grape shaped chorionic villus areas, consist signs of molar pregnancy [7]. Coexistence of these histopathologic entities did not affect or transform the therapeutic mapping. Assiduous clinical and laboratory evaluation of the patient in order to exclude areas of metastatic trophoblastic disease [8]. Monitoring of clinical ranges of b HCG (beta- chorionic gonadotropin), thorax X-ray, abdominal ultrasound evaluation, compose evidence of therapeutic strategy [9].

\section{Conclusion}

Trisomy 18 or Edwards Syndrome, represents a rare entity, with most of cases resulting in endometrial death. Gold standard consists immediate termination of pregnancy and therapeutic uterine evacuation. Scientific guidance and experience in fetal medicine represent necessary conditions in order to establish proper diagnosis and treatment.

\section{Disclosure of interest}

All authors declare any financial interest with respect to this manuscript.

\section{References}

1. Goel N, Morris JK, Tucker D (2019) Trisomy 13 and 18-Prevalence and mortality-A multi-registry population based analysis. Am J Med Genet A 179: 2382-2392. [Crossref]

2. Du Y, Lin J, Lan L (2018) Detection of chromosome abnormalities using current noninvasive prenatal testing: A multi-center comparative study. Biosci Trends 12: 317 324. [Crossref]

3. Deng Q, Li R, Fu F (2018) Prenatal diagnosis of trisomy 18 rescue resulting in mosaic of two different diploid cell lines in a hydropic fetus. Eur J Obstet Gynecol Reprod Biol 224: 209-211. [Crossref]

4. Cammarata-Scalisi F, Lacruz-Rengel MA, Araque D (2017) Mosaic trisomy 18. Series of cases. Arch Argent Pediatr 115: e183-e186. [Crossref]

5. Cereda A, Carey JC (2013) The trisomy 18 syndrome. Fetal Pediatr Pathol 32: 133150

6. Moore GE, Ruangvutilert P, Chatzimeletiou K (2000) Examination of trisomy 13, 18 and 21 foetal tissues at different gestational ages using FISH. Eur J Hum Genet 8 : 223-228. [Crossref]

7. Stamatopoulos N, Espada Vaquero M, Leonardi M (2020) Pre-operative classification of molar pregnancy: How good is ultrasound? Aust $N$ Z J Obstet Gynaecol 17. [Crossref]

8. Lin LH, Polizio R, Fushida K (2019) Imaging in gestational trophoblastic disease. Semin Ultrasound CT MR 40: 332-349. [Crossref]

9. Promberger R, Ott J, Chalubinski KM (2016) Ten-year experience with the conservative management of abnormally invasive, residual trophoblastic disease. A retrospective case series. Gynecol Obstet Invest 81: 375-380. [Crossref]

Copyright: (C2020 Sofoudis C. This is an open-access article distributed under the terms of the Creative Commons Attribution License, which permits unrestricted use, distribution, and reproduction in any medium, provided the original author and source are credited. 